REVISTA DE GEOCIÊNCIAS DO NORDESTE

Northeast Geosciences Journal

v. 7, no 2 (2021)

ISSN: 2447-3359

https://doi.org/10.21680/2447-3359.2021v7n2ID21231

\title{
AGRICULTURA DE SUBSISTÊNCIA E MUDANÇAS CLIMÁTICAS: CASOS DOS DISTRITOS DE MAGUDE E MOAMBA (SUL DE MOÇAMBIQUE)
}

\section{Orlando Inácio Jalane ${ }^{1}$; Edson Vicente da Silva ${ }^{2}$; Carlos Henrique Sopchaki ${ }^{3}$}

${ }^{1}$ Mestrado em Geografia, Departamento de Agronomia e Recursos Naturais, Instituto de Investigação Agrária de Moçambique (IIAM), Maputo/Mocambique.

ORCID: https://orcid.org/0000-0001-5638-0311.

Email: ojalane@gmail.com

${ }^{2}$ Doutor em Geografia, Departamento de Geografia, (UFC), Fortaleza/CE, Brasil.

ORCID: https://orcid.org/0000-0001-5688-750X.

Email: cacauceara@gmail.com

${ }^{3}$ Doutor em Geografia, Departamento de Geografia, UFC, Fortaleza/CE, Brasil.

ORCID: https://orcid.org/0000-0001-8127-4529.

Email: carlos.geografia@ufc.br

\section{Resumo}

O presente ensaio aborda os efeitos das mudanças do clima na agricultura de subsistência (familiar) moçambicana, em terras com tendências climáticas semiáridas, como são os distritos a sul de país, casos de Magude e Moamba, na província de Maputo. A pesquisa foi desenvolvida a partir de levantamentos bibliográficos e observação direta dos autores, que vivenciaram a realidade local. Existe uma tendência cíclica de anos de seca extrema, precididos por outros de excessos de precipitação e ligeira concentração em períodos cada vez mais curtos, o que dificulta a capacidade dos solos de absorverem os impactos das águas. No presente trabalho busca-se evidenciar a grande exposição da agricultura de subsistência em regiões semiáridas, face aos cenários climáticos adversos e como isso pode impactar na vida dos agricultores e suas famílias, bem como na dieta alimentar do país.

Palavras-chave: Agricultura de subsistência; Semiárido; Mudanças climáticas.

\section{SUBSISTENCE AGRICULTURE AND CLIMATE CHANGE: CASES OF THE MAGUDE AND MOAMBA DISTRICTS (SOUTH OF MOZAMBIQUE)}

\begin{abstract}
This essay addresses the effects of climate change on Mozambican (family) subsistence agriculture, in lands with semiarid climate trends, such as the south districts of the country, as Magude and Moamba, in Maputo province. The research was developed from bibliographical surveys and direct observation of the authors, who experienced the local reality. There is a cyclical trend of years of extreme drought, preceded by others of years like excess precipitation and slight concentration in increasingly shorter periods, which hinders the capacity of soils to absorb the impacts of water. The present work seeks to highlight the great exposure of subsistence agriculture in semi-arid regions, given the adverse climatic conditions and how it can impact the lives of farmers and their families, as well as the country's diet.
\end{abstract}

Keywords: Subsistence agriculture; Semiarid; Climatic changes.

AGRICULTURA DE SUBSISTENCIA Y CAMBIO CLIMÁTICO: CASOS DE LOS DISTRITOS DE MAGUDE Y MOAMBA (SUR DE MOZAMBIQUE)

\section{Resumen}

Este ensayo aborda los efectos del cambio climático en la agricultura de subsistencia (familiar) de Mozambique, en tierras con tendencias climáticas semiáridas, como los distritos al sur del país, como Magude y Moamba, en la provincia de Maputo. La investigación se desarrolló a partir de encuestas bibliográficas y la observación directa de los autores, que experimentaron la realidad local. Existe una tendencia cíclica de años de sequía extrema, precedida por otros de años, como el exceso de precipitación y la ligera concentración en períodos cada vez más cortos, lo que dificulta la capacidad de los suelos para absorber los impactos del agua. El presente trabajo busca mostrar la gran exposición de la agricultura de subsistencia en regiones semiáridas, dados los escenarios climáticos adversos y cómo esto puede afectar las vidas de los agricultores y sus familias, así como la dieta del país. 
Palabras-clave: Agricultura de subsistencia; Semiárido; Cambios climáticos.

\section{INTRODUÇÃO}

Moçambique é um país da costa oriental de África, e de acordo com o censo demográfico de 2017 , o país tem cerca de 28 milhões de habitantes e mais da metade dessa população vive nas zonas rurais, dependendo da agricultura para a sua sobrevivência (INE,2018). As estimativas apontam que há disponibilidade de cerca de 36 milhões de hectares de terras aráveis, das quais estão em uso apenas cerca de $15 \%$. Mais de $99 \%$ da área agrícola é constituída por explorações de menos de 10 hectares e a maior parte da terra é administrada segundo normas costumeiras (CARRILHO, ABBAS, CHIDASSICUA, \& MOSCA, 2015).

Em Moçambique, a maior parte da terra produtiva se encontra na posse dos pequenos agricultores e da agricultura familiar, o que torna esses escalões como os maiores contribuintes da dieta do país. A grande dependência da agricultura moçambicana de produções familiares de pequena escala a coloca em situações de fragilidade aos impactos atuais e futuros das mudanças climáticas, fato que está a representar um retrocesso nos projetos de desenvolvimento dos países periféricos e em particular as regiões de climas seco com um balanço hídrico negativo como os casos de uma parte do território a sul de Moçambique.

Segundo Smit \& Skinner (2002), o clima representa uma poderosa restrição ambiental em grande parte das atividades humanas, sendo que a agricultura e a produção de alimentos é um dos sistemas humanos com maior probabilidade de ser afetado pelas mudanças climática. Levando-se em consideração que a agricultura é o elo mais fraco das mudanças do clima, então o cenário Moçambicano se agrava, visto que grande parte da sua população vive e depende dela.

Com exceção da Província de Zambézia, na fronteira com o Malawi, onde em algumas pequenas regiões chega a chover mais de $2.000 \mathrm{~mm} / \mathrm{ano}$ e do norte da Província de Niassia (norte de Moçambique), onde há registros de mais de $1.600 \mathrm{~mm} / \mathrm{ano}$, a maioria do país apresenta chuvas anuais variando entre cerca de 600 e 900 mm/ano (EMBRAPA, 2020). O período mais chuvoso ocorre nos meses de dezembro a março e coincide com o verão quente, sendo que no resto do ano a precipitação é baixa, portanto mais seco. Os níveis elevados de evapotranspiração potencial, que superam a precipitação média anual colocam os distritos de sul de Moçambique entre os altamente vulneráveis aos fatores climáticos e segundo o Quarto Relatório de Avaliação do International Panel on Climate Change (IPCC) (IPCC, 2007).

Segundo o MASA (2016), aponta para existência de cerca de 4 milhões de explorações agrícolas em Moçambque, dos quais 3.9 milhões que corresponde a $98.7 \%$ das explorações estão nas maões dos pequenos agricultores e os restantes $1.3 \%$ eram explorada pelas médias e grandes explorações. O mesmo relatório indica que a área cultivada nesse período era de 4,8 milhões de héctares.

Esta grande concentração da agricultura do país nas mãos dos pequenos agricultores, cujos objetivos centrais estão voltados para a sua própria sobrevivência e existência, com o acesso restrito as tecnologias agrárias apropriadas para fazer face as suas necessidades de produção, acresce os riscos da mesma aos novos cenários climáticos.
Para muitos autores a exposição da agricultura africana e particularmente moçambicana aos riscos naturais não está inserida apenas nas alterações do clima (padrões de chuvas, aumento da temperatura, etc.). Segundo Morton (2007, p.1, tradução nossa ):

Alguns dos impactos mais importantes da mudança climática global serão sentidos entre as populações, predominantemente em países em desenvolvimento, conhecidos como agricultores de "subsistência" ou "pequenos agricultores". Sua vulnerabilidade às mudanças climáticas vem tanto da localização predominante nos trópicos quanto de várias tendências socioeconômicas, demográficas e políticas que limitam sua capacidade de adaptação à mudança.

Existe uma grande dependência natural da agricultura de subsistência Moçambicana, que tem influenciado o estágio do desenvolvimento da atividade agrária em toda extensão nacional, particularmente em regiões com dificuldade relacionadas à disponibilidade das fontes de águas e solos produtivos, portanto com déficit hidrológico acentuado, como são os casos dos distritos inseridos na Província de Maputo, com chuvas anuais acumuladas apresentando índices baixos, de até somente 656 mm/ano (EMBRAPA, 2020)

Os riscos sempre foram parte das atividades antrópicas desde os primórdios, mas não se pode negar que aumentaram a periodicidade de ocorrência, fator que tem pesado cada vez mais nas atividades com grande dependência dos fatores naturais, e a agricultura familiar/subsistência tem sido dos mais afetados por este flagelo, como é o caso dos produtores rurais inseridos nos distritos de Magude e Moamba.

Portanto, para analisar essa problemática dentro da agricultura de Moçambique o foco do presente estudo se dará em uma dimensão territorial local e com grandes influências urbanas: os distritos de Magude e Moamba, localizados na região sul do país e inseridos na província de Maputo. Cabe destacar ainda que esses distritos fazem parte dos principais fornecedores de produtos agrícolas à capital do país, a cidade de Maputo.

\section{AGRICULTURA DE SUBSISTÊNCIA MOÇAMBICANA}

Não é possível descrever ou abordar a temática da agricultura de subsistência na África sem que antes clarifique os conceitos de subsistência e agricultura familiar. Segundo Correia (2012, p. 121) existem elementos claros para separar os dois sistemas agrários.

Agricultura familiar se diz que, mantendo muito dos traços da agricultura de subsistência ou tradicional ou seja, embora fortemente condicionada pelas determinantes naturais $\mathrm{e}$ socioeconómicas endógenas, vai estando, cada vez mais ligada aos mercados isto é, influenciado pelas determinantes socioeconómicas exógenas. Os sistemas de subsistência, como o nome indica, são sistemas que visam fundamentalmente a sobrevivência do agregado familiar o que os torna muito mais resistentes a qualquer mudança. Naturalmente que os condicionalismos que podem levar ao desaparecimento do sistema poderão ter razões que não se prendem apenas com as questões técnicas como por exemplo os conflitos armados. Pelo seu lado, a agricultura comercial é, no essencial, uma atividade económica que faz da venda da produção a sua prioridade. 
Portanto, conforme Correia (2012), há uma ligeira diferença entre a agricultura familiar, que é baseada na sua integração ao mercado de produtos locais e de exportação; e o conceito de subsistência, que se revela com uma ligeira exclusividade ao sustento básico da família.

A agricultura de subsistência africana é tida como um elemento de existência das famílias, com muitos poucos de incentivos externos para o seu progresso.

$\mathrm{Na}$ agricultura moçambicana, e na maior parte da região africana, os termos agricultura de subsistência e agricultura familiar são normalmente considerados sinônimos.

Em Moçambique a atividade agrária, segundo ao artigo 103 da Constituição Geral da República de Moçambique:

1: "...é a base do desenvolvimento nacional".

2: O Estado garante e promove o desenvolvimento rural para a satisfação crescente e multiforme das necessidades do povo e o progresso económico e social do país.

Em contraste ao artigo 103 da Constituição da República, Moçambique pós independência fez poucos investimentos no setor base da economia do país. Poucos esforços foram feitos com vista à promoção do desenvolvimento do setor agrário. As grandes plantações herdadas do sistema colonial português foram ao colapso logo depois da independência nacional, derivados de vários fatores.

A agricultura de subsistência, que no contexto moçambicano é equiparada à agricultura familiar, reforça a sua importância no meio da agricultura do país, sendo ela responsável por empregar mais de $65 \%$ da população em idade produtiva. Segundo Mosca (2014), a falta de investimento na agricultura africana é responsável pelos níveis elevados de pobreza que assolam o continente há décadas.

A insegurança e a necessidade de ajuda alimentar são cíclicas devido a vários fatores, como políticas adversas ("não amigas") ao setor agrário, conflitos e deslocados de guerra, efeitos das mudanças climáticas, sendo a África uma das zonas de maior risco (Mosca, 2014).

Os escassos investimentos por partes das autoridades Moçambicanas, aliados às atuais mudanças nos padrões das chuvas e da temperatura vêm trazendo novos desafios para a agricultura de subsistência. A localização destes distritos no cinturão africano do semiárido aumenta a sua exposição aos efeitos climáticos futuros na agricultura de subsistência. A Figura 2 traz a localização da área de estudo e a Figura 1 apresenta a distribuição do clima semi-árido na África, onde pode-se observar o enquadramento de parte da área de estudo no clima semiárido quente.
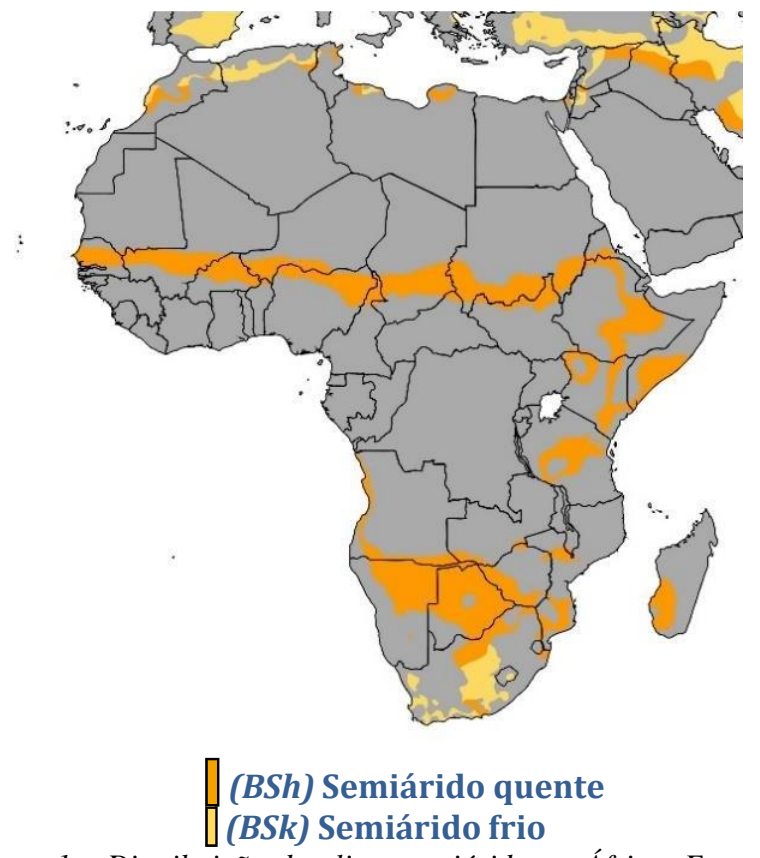

Figura 1 - Distribuição do clima semiárido na África. Fonte: adaptado de https://pt.wikipedia.org/wiki/Classifica (2020)

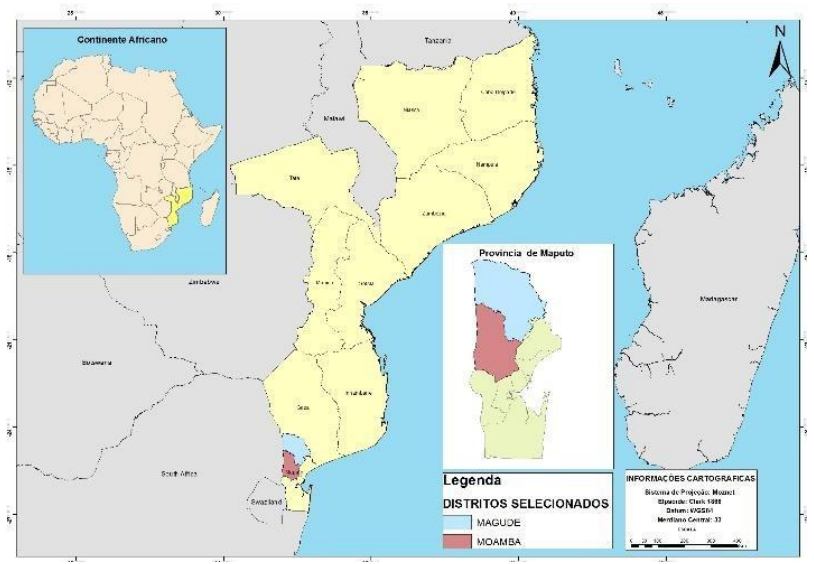

Figura 2 - Enquadramento territorial de Moçambique e distritos alvos no contexto Africano e Nacional. Fonte: Os Autores (2020). 
Jalane, O. I.; Silva, E. V.; Sopchaki, C. H., Rev. Geociênc. Nordeste, Caicó, v.7, n.2, (Jul-Dez) p.123-130, 2021 126

\section{OS DISTRITOS DE MAGUDE E MOAMBA, PRODUTORES E FORNECEDORES DE PRODUTOS AGRÍCOLAS}

Os distritos de Magude e Moamba estão localizados a Noroeste da província de Maputo, com distrito de Magude mais ao norte da província de Maputo, fazendo limite com a província de Gaza (MAE, 2005).

O distrito de Moamba possui uma superfície territorial de $4.623 \mathrm{Km} 2$, ocupado na sua totalidade por assentamentos rurais. Segundo MAE (2014), do ponto de vista climático, o distrito da Moamba apresenta dois subtipos de clima segundo a classificação de Koppen, que são os tipos BS (Clima de estepe), com uma temperatura média anual que os $24^{\circ} \mathrm{C}$ e pluviosidade anual entre 580 a $590 \mathrm{~mm}$ e, também, junto à fronteira com Ressano Garcia e o clima do tipo BSW, Clima de estepe com invernos secos e uma temperatura média anual entre 230 a $240 \mathrm{C}$, e baixa pluviosidade em comparação ao resto do distrito.

Portanto, se evidenciam duas estações no distrito, uma quente e chuvosa que se estende de outubro a março e, outra fresca e seca que vai de abril a setembro. A precipitação anual média é de cerca de $517 \mathrm{~mm}$, que se concentra de dezembro a Janeiro, sendo que a evaporação potencial média anual é elevada com cerca de 1.433 $\mathrm{mm}$ a $1.500 \mathrm{~mm}$, bastante elevada para a realidade pluviométrica da região.

A prática da atividade agrária no distrito de Moamba, principalmente aquela que é praticada utilizando sistemas de irrigação, é feita como base nas águas do Rio Incomáti, que atravessa o distrito, vindo da África do Sul no planalto de

Transvaal e, entra em Moçambique pela Garganta de Komatipoort e vai desaguar nas proximidades da Vila de Marracuene. Os seus afluentes em Moçambique são o Massintonto e o Sábiè localizados a norte do distrito (MAE, 2014).

A irrigação é basicamente feita por agricultores associados, que se beneficiam do apoio técnico da Açucareira de Xinavane (AdX) para a produção da cana sacarina. As culturas de sustento e rendimento familiar continuam nos moldes tradicionais de produção, em solos mais pobres e secos e sujeitos à escassez da precipitação e de técnicas melhoradas

A grande maioria dos agricultores recorre às terras baixas dos rios para o cultivo agrícola nos distritos de Moamba e Magude, para manter os solos úmidos durante uma grande parte do ano, que também são as terras preferenciais das grandes companhias agrárias, que se encontram instaladas nesses distritos. Se destacam as terras baixas dos rios Incomati e do Sábie, onde em grande parte da sua extensão se encontra instalada a maior companhia de produção de açúcar da região sul do país (Açucareira de Xinavane - AdX), por apresentarem uma disponibilidade maior de água e terras ótimas para agricultura.

O distrito de Magude é o maior da província de Maputo, com quase $7.000 \mathrm{Km} 2$, na sua maioria localizados em regiões planas com cotas inferiores a 100m. Predomina o clima de estepe local, e ao longo do ano existe pouca precipitação com uma média anual de $712 \mathrm{~mm}$ e elevada taxa de evaporação potencial média anual que é de cerca de $1528 \mathrm{~mm}$. De acordo com a clissificação climática de Köppen, o clima é BSh (clima das estepes quentes) de baixa latitude e altitude e a temperatura média anual em Magude é $23.3^{\circ} \mathrm{C}$.
Assim como Moamba, Magude é também atravessado pelo rio Incomati, favorecendo a prática da atividade agropecuária e a pesca, fato que permitiu a instalação de uma rede de irrigação, que cobrem uma área de 3.744 hectares, explorados na sua maioria pelos pequenos agricultores para a produção de cana sacarina, através de fomento da Açucareira de Xinavane, que é o um dos principais produto agrícola do distrito (MAE, 2014).

A agricultura é a base da economia dos distritos, tendo como principais culturas as hortícolas, milho, mandioca, feijão, e cana sacarina. A criações predominantes são de bovinos, ovinos e aves, destinadas para o consumo familiar e comercialização.

O setor agrícola familiar destes distritos está em expansão, e as explorações privadas, que ocupam uma parte significativa das terras férteis e absorvem mais da metade da mão-de-obra assalariada dos mesmos.

No Quadro 1 há uma amostra da importância do setor familiar ou da agricultura de subsistência na agricultura local. Cabe destacar, conforme já exposto anteriormente, que ainda há uma certa resistência na equiparação desses dois termos porque está claro que em Moçambique assim como na maior parte da África subsaariana os dois termos são bastantes coincidentes para a maior parte das suas populações, pois não existe uma agricultura exclusivamente de subsistência sem pequena tendência aos mercados por mais pequeno que seja.

Quadro 1 - Número de Explorações Agropecuárias por Tipo; Áreas Cultivadas no Total da Província de Maputo em 2015. Fonte: adaptado dos dados do MASA (2016).

\begin{tabular}{|c|c|c|}
\hline $\begin{array}{c}\text { Tipo de } \\
\text { Explorações }\end{array}$ & $\begin{array}{c}\text { Número de } \\
\text { Explorações }\end{array}$ & Área Cultivada (hectares) \\
\cline { 1 - 1 } Pequenas & 775,971 & 207,629 \\
\cline { 1 - 1 } Médias & & \\
\cline { 1 - 1 } Grandes & 252 & 21514 \\
\hline
\end{tabular}

A analise do quadro, indica que a maior procemtagem da área cultivada em 2015 havia sido feita pelos agricultores familiares com uma legeira participação da agricultura de média exploração, e correspondia a $90.6 \%$ da área total cultivada e com mais de 775971 explorações que foram contabilizados nesse período, representado mais de 207629 hectares feitos pela agricultura familiar e explorações médias da província de Maputo, fato que reforça a importância da agricultura familiar para o sustento da população moçambicana.

Esses números apontados nesses dados levantados podem não constituir a real situação de Moçambique, segundo Catsossa (2017, p.155),

[ ] a partir dos anos de 2007/8, devido à crise de preços de alimentos verificado neste período. Foi, no entanto, a partir desta altura, que o meio rural moçambicano, começou a ser marcado por uma intensificação de práticas atreladas ao modelo capitalista de produção - o agronegócio.

Essa constatação pode ser justificada pelo relatório da UNAC $\&$ GRAIN (2015, p. 1), que conclui que desde 2006 foram feitos pelo menos 36 negócios com investidores estrangeiros para a 
produção de cultivos alimentares, no espaço de mais de 1,5 milhões de hectares.

Segundo o Sitoe (2005), Mocçabique possui um potencial agrário de Cerca de 36 milhões de héctares (ha) de terra arável, dos quais menos de $10 \%$ são cultivados o que corresponde a 6 milhões hectares. A entrada desses investimento das multinacionais agrárias, vieram ocupaar uma parte das áreas outrora pertencente a agricultura familiar, mais ainda não foram capaz de ocupar o lugar destes como os responsáveis pela suberania alimentar da grande parte dos moçambicanos. Portanto ainda estaria nas mãos dos agricultores familiares moçambicanos mais de $73.7 \%$ da terra cultivada do país, com as grandes explorações viradas para a produção de commodities para exportação, a agricultura camponesa fica a responsável pela segurança alimentar do país.

\section{SISTEMAS AGRÁRIOS}

Para Sitoe (2008), a análise dos sistemas agrários de um determinado lugar parte do pressuposto de que analisar e explicitar um objeto é também estudar a sua dinâmica de evolução através do tempo e as relações que esse sistema mantém com o resto do mundo nos seus diferentes estágios de evolução. Mas não é o objetivo central desse texto fazer a proposta de análise temporal da evolução dos sistemas agrários, mas uma pequena descrição delas com o objetivo de ter o melhor entendimento da sua vulnerabilidade aos eventos climáticos.

Os distritos de Magude e Moamba se inserem na lógica agrária nacional, maioritariamente familiar, pouco uso das tecnologias agrárias avançadas e sem grandes incentivos externos, tanto do estado, como do setor privado. Pouco mais de $70 \%$ da sua população ativa depende do cultivo da terra, feito de forma tradicional e com grande dependência das condições climáticas.

Neste texto analisa-se sistemas agrários, relacionados as diferentes formas de produção e organização do mesmo . Os distritos apresentam dois tipos distintos de sistemas agrários, o sistema irrigado, e o sistema de sequeiro.

Cabe destacar que o sistema agrário pode ser definido como um modo de exploração do meio historicamente constituído, um sistema técnico adaptado às condições bioclimáticas de um espaço determinado, que responde às condições e às necessidades sociais no momento. Um modo de exploração do meio que é o produto específico do trabalho agrícola, utilizando uma combinação apropriada de meios de produção inertes e meios vivos para explorar e reproduzir um meio cultivado, resultante das transformações sucessivas sofridas historicamente pelo meio natural (MAZOYER; ROUDART, 1999 apud AMILAI, 2008).

O sistema irrigado é praticado na planície dos rios Incomati e Sábie, ou através de canos de irrigação, na sua grande maioria instalados pela Açucareira de Xinavene, como fomento da produção de cana açucar, junto às associações de agricultores e ao longo dos cursos de água de vários pequenos riachos, onde encontram-se as pequenas e médias empresas agrárias nos dois distritos.

O sistema de sequeiro é praticado nas terras marginais, com dependência exclusiva das condições naturais, o qual tem o efeito mais severo para os agricultores familiares. É caracterizado basicamente por desflorestamento constante através de queimadas das savanas, como forma de limpeza dos campos. O sistema urbanizado agrário seria o último que se destaca na produção avícola e na horticultura, voltado essencialmente para o consumo urbano.

Mais de $80 \%$ dos agricultores familiares dos distritos de Magude e Moamba ainda recorrem ao uso das técnicas de produção rudimentares, como são os casos da prática de queimadas, lavouras e sementeiras manuais, conforme pode se observar na figura 3.

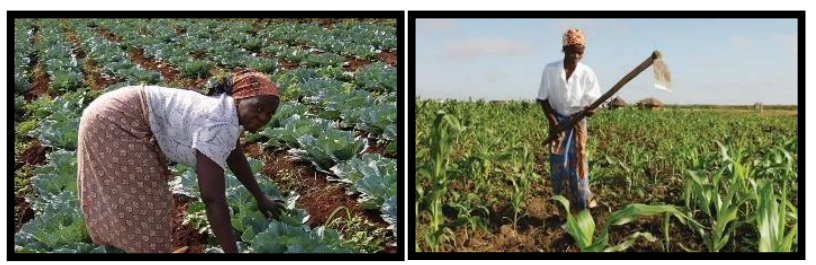

Figura 3 - Exemplos de técnicas de produção da agricultura familiar nos distritos de Magude e Moamba: à esquerda Campos de hortícolas ao longo da baixa de Sábié; à direita produção em sequeiro, com uso de enxada.

\section{FATORES DE RISCO DA AGRICULTURA DE SUBSISTÊNCIA}

A mudança climática é o novo inimigo dos países em via de desenvolvimento, principalmente países costeiros como é o caso de Moçambique, que já vem experimentando os efeitos da mudança do clima com cada vez mais severidade. A agricultura moçambicana é pouco desenvolvida no sentido tecnológico, dependente, na sua totalidade, das condições naturais do clima, fazendo dela uma atividade de grandes riscos e por isso com pouca atração de investimentos tantos públicos, principalmente os privados. Contudo, estes não são os únicos fatores que explicam os poucos investimentos feitos e a falta de atrativos para a exploração agrária moçambicana.

A combinação de uma seca de longa duração, rápida urbanização e crescimento populacional está aumentando a pressão sobre o já limitado suprimento de água doce para Maputo e outras cidades costeiras.

As comunidades continuam dependendo fortemente da agricultura baseada na queda normal das chuvas para a produção de alimentos. "O milho não cresce e a chuva é menos frequente, as pessoas estão cultivando milho em campos secos" fala de um agricultor em uma entrevista ao canal tv local (STV, Jornal da noite do dia 02/03/2019 $)$.

$\mathrm{O}$ rápido crescimento das áreas urbanas tem sido um dos grandes desafios da produção agrária, segundo Mosca (2014, p.2):

A urbanização, motivada por diferentes razões, económicas e não-económicas, tem provocado êxodos de diferentes dimensões sem serem acompanhados das transformações estruturais que permitam o aumento da produção e produtividade, para suprir a demanda de alimentos das cidades, o que é agravado por taxas de crescimento populacional, geralmente elevadas.

\footnotetext{
${ }^{1}$ Disponivel em: https://www.youtube.com/watch?v=tEVra_aEWI
} 
As políticas agrárias nacionais têm sido apontadas como um dos grandes entraves para o desenvolvimento agrário nacional, principalmente da agricultura familiar moçambicana, contudo as mesmas não são os únicos obstáculos. Segundo Smit e Skinner (2002) citando Parry e Carter (1989) e Reilly (1995), a agricultura é inerentemente sensível às condições climáticas e está entre os setores mais vulneráveis aos riscos e impactos das mudanças climáticas globais. Este cenário por si só já era alarmante, contudo o mesmo vem se agravando nos países com poucos recursos e com a falta de vontade política para impulsionar a agricultura. De acordo com a declaração de Maputo em 2013, a União Africana (UA), sugeriu aos governos africanos que alocassem à agricultura e desenvolvimento rural pelo menos $10 \%$ do orçamento do Estado para o desenvolvimento das atividades agrárias nos seus territórios a favor dos pequenos agricultores (MOSCA, 2014). Para se ter uma ideia segundo Aiuba \& Mosca (2018), o estado moçambicano no intrevalo de 2010 a 2018, o orçamento alocado a agricultura não ultrapassou o tecto de $5 \%$, que é a metade do proposto na declaração de Maputo, apenas no ano de 2019 atingiu os $6.4 \%$ do orçamento geral do país.

Smit e Skinner (2002, p.88), reforçam a situação impactante da falta de investimento dentro da agricultura dos países em desenvolvimento:

Apesar da importante influência das mudanças climáticas, incluindo variabilidade e além disso, a adaptação na agricultura não funciona e evolui com respeito apenas a esses estímulos climáticos. Forças não-climáticas, como condições econômicas, políticas, meio ambiente, sociedade e tecnologia, têm implicações significativas para a tomada de decisão agrícola, incluindo a tomada de decisão adaptativa.

Isso reforça o fato de que os poucos investimentos para o desenvolvimento agrário em Moçambique tem contribuído para a exposição dessa, aos fatores externos, sejam eles climáticos ou não. Não é só a falta de políticas agrárias mais claras que deixam a agricultura moçambicana à mercê dos problemas climáticos, mas também a falta de programas de organização territorial que levem em consideração o real potencial do território.

Esse deficiente planejamento territorial tem contribuído na pressão do urbano sobre o rural, com maior intensidade sobre as áreas de grandes proximidades aos núcleos urbanos centrais, como são os casos do distrito de Moamba e Magude, que podem ficar ainda mais suscetíveis aos impactos das mudanças climáticas.

\section{O IMPACTO DAS ALTERAÇÕES CLIMÁTICAS NOS SISTEMAS AGRÍCOLAS}

Há muitas discussões no que se refere aos padrões das mudanças climáticas sobre as atividades agrárias. Para Smit e Skinner (2002), a especificidade do lugar e do contexto das adaptações agrícolas, indicam que será improvável que a maioria das adequações às mudanças climáticas sejam efetivadas independentemente de iniciativas relacionadas à gestão de riscos, visto que os cenários convencionais de impacto climático geralmente se concentram nas mudanças na temperatura média e na humidade.
Apesar do atual cenário e aumento da temperatura, é também verdade que a grande preocupação da agricultura de subsistência moçambicana se volta a períodos cada vez mais frequentes de seca extrema ou de excesso de chuvas. Os agricultores apontam os fenômenos de escassez e excessos de água como os mais impactantes à atividade agrária em Moçambique, principalmente na região sul do país.

Estrato de uma entrevista de um produtor de gado ao jornal o País no distrito de Magude:

Eu não estava preparado para enfrentar a seca. Estava habituado aos anos normais em que são alguns meses ou um ano e depois chove. E também nós tivemos uma guerra e isto estava tudo deserto, não havia população e nem havia necessidade de fazer confinamento de gado porque quando não havia pasto num lado, havia noutro. Agora há mais população e muito gado e há escassez de pasto. Esta seca veio agudizar. (Langa, 2017).

Os agricultores de subsistência são atualmente submetidos a novas realidades climáticas que vem modificando os seus hábitos de plantio, o que se dá pela alteração do período normal das chuvas, fator que afeta o período de crescimento das culturas. Isso faz com que eles se preocupem no que tange à sobrevivência das famílias nestes distritos, já que convivem com a escassez. Essa realidade pode se agrvar divido aos cenários climaticos futuros previstos.

Os impactos da mudança climática global serão sentidos entre as populações, predominantemente em países em desenvolvimento, conhecidos como agricultores de "subsistência" ou "pequenos agricultores" (MORTON, 2007). A vulnerabilidade desses às mudanças climáticas vem tanto da localização predominante nos trópicos quanto de várias tendências socioeconômicas, demográficas e políticas que limitam sua capacidade de adaptação à mudança.

As prováveis mudanças climáticas esperadas para África Oriental também podem impactar profundamente as populações e economias dessa região, sendo que as principais mudanças estão relacionadas à alterações na frequência, intensidade e previsibilidade das chuvas e temperatura (UELE, LYRA, \& DE OLIVEIRA JÚNIOR, 2017).

O cenário atual da agricultura de subsistência no sul de Moçambique, e particularmente nos distritos de Magude e Moamba é caracterizado pela seca cíclica, com expoente nos últimos 20 anos, condicionando a capacidade de produção para o sustento de muitas famílias que dependem quase que exclusivamente da atividade agrária.

Os efeitos das mudanças climáticas na agricultura Moçambicana ultrapassam as dimensões dos agricultores familiares, pois as empresas agrárias de médio porte instaladas nestes distritos têm experimentado diversas dificuldades no processo de produção devido à escassez de água no único reservatório disponível para o abastecimento das atividades agrárias.

Nos últimos anos a maior empresa de produção e exportação de banana de Moçambique, a Bananalândia, anunciou a redução da sua capacidade de produção em cerca de $50 \%$, indo de 300 mil toneladas por unidade de produção para 150 mil toneladas por unidade de produção, devido ao fenômeno climático da escassez das chuvas na região sul de Moçambique (MACAUHUB, 2018). 
A produção de sustento nos distritos de Magude e Moamba na campanha agrícola 2018/9 foi severamente afetada pela falta das chuvas, o que levou à perda de mais de 6000 hectares de milho e 300 hectares de amendoim, culturas de extrema importância para a região sul de Moçambique (STV, Jornal da noite do dia $02 / 03 / 2019^{2}$ ). A escassez da água tem-se tornado um fenômeno cada vez mais crescente no seio das comunidades rurais e urbanas de Moçambique, e não afeta somente a agricultura, como também atividades urbanas que dependem da sua disponibilidade.

Esse processo de escassez tem sido contrastado pelo excesso através das cheias cíclicas que devastam campos com culturas diversas ano após ano. De acordo com o Coelho (2004, p. 2018):

Moçambique tem sido vítima particular de variações climáticas bruscas, sofrendo regularmente o flagelo de secas, chuvas torrenciais com cheias, e ventos ciclónicos. Nos vinte e cinco anos de independência o país foi atingido por duas violentas secas com a duração de mais de dois anos cada uma, pelo menos dezasseis ciclones registados e várias cheias, duas das quais de grandes dimensões.

Esses eventos têm condicionado a agricultura familiar Moçambicana, que vem enfrentando grandes desafios nos últimos anos desde a virada do século XXI, com cada vez menos capacidade produtiva, que chega a colocar em perigo o sustento familiar e a sua subsistência, fato que se tornou mais preocupante nos últimos 20 anos, devido à secas severas (CEMO, 2010).

Essas condições de secas e déficit de chuva têm resultado em grandes perdas da produtividade agrícola (MATYAS E SILVA, 2013), mas também os período de excesso da água constituem um problema com grande impacto negativo na produção agrícola do que em relação a períodos de chuvas abaixo do normal em Moçambique (REASON, 2007). Atualmente, os agricultores dos distritos Noroeste da província de Maputo vivem em condições extremamente difícil, basicamente sem as condições mínimas de garantir a sobrevivência dos membros das suas famílias e muito menos do gado que se encontra sobre a sua posse, devido à redução dramática das áreas de pasto nesses distritos, por conta da seca que tem assolado os distritos de Magude e Moamba.

\section{CONSIDERAÇÕES FINAIS}

Durante a presente análise ficou evidente a real situação de exposição de Moçambique aos eventos climáticos extremos, resultante da mudança global do clima. Estes impactos serão mais severos na atividade agrária, ainda mais quando se considerada que tal atividade em Moçambique é pouco desenvolvida tecnologicamente e portanto, depende exclusivamente das condições naturais (agricultura de sequeiro), e a sul do país é agravado pelas condições de seca severa. Urge então uma necessidade de desenho de políticas agrárias com vistas a ajudar aos agricultores familiares nacionais a mitigar os efeitos das mudanças cada vez mais devastadores para a agricultura moçambicana.

Cabe destacar que este cenário já pesam nos modos de produção das comunidades que vivem na dependência, principalmente aqueles que praticam a agricultura familiar, potencialmente em regiões com características semiáridas.

O nível de exposição ao efeito anômalo das mudanças sobre os agricultores de subsistência dos distritos de Magude e Moamba atingiu níveis bastante altos nos últimos 20 anos, desde as grandes cheias dos anos 2000 na região sul de Moçambique. As discussões em torno da agricultura moçambicana apontam para algumas possíveis soluções, que tem sido aclamadas por vários seguimentos acadêmicos nacionais, como por exemplo o aumento da capacidade das represas para a conservação da água, que em períodos de chuvas excessivas provocam danos sócio-ambientais severos.

Aponta-se também algumas preocupações relacionadas à real efetividade destas ações diante às mudanças do clima, questionase se seria realmente efetivo aumentar a capacidade de represionamento sem que adotemos as comunidades de ferramentas adequadas para o uso sustentável desse recurso e de tantos outros que são chaves para uma melhor adaptabilidade da mitigação dos efeitos climáticos.

A situação atual do país em relação à agricultura exige um comprometimento de todos os interessados. Desdes as comunidades e os órgãos públicos locais e centrais responsáveis pela implementação das politicas publicas.

É dever do Estado colaborar com maior investimento e compromisso com a agricultura nacional, através do incremento do orçamento destinado a este setor, principalmente uma maior atenção aos agricultores familiares, já que esses colaboram com a segurança alimentar do país.

As mudanças são uma preocupação à frágil economia de Moçambique, baseada ainda em grande escala no agrário, o qual tem sofrido efeitos danosos, devido a pouca atenção que tem sido dispensada a esse setor. $O$ maior desafio da agricultura moçambicana, e em particular dos distritos estudados, ainda tem uma grande dependência da mesma aos fatores naturais, ao uso restrito de insumos de qualidade, à falta de políticas que busque e incentivem o melhoramento da fertilidade dos solos e à fraca capacidade de irrigação dos campos agrícolas.

\section{REFERÊNCIAS}

AIUBA, R.; MOSCA, J. Orçamento geral do estado para o sector agrário e desenvolvimento rural. OMR. Destaque rural $n^{\circ} 46$. 2018.

AMILAI, C. M. Evolução e Diferenciação De Sistemas Agrários: Situação E Perspectivas Para A Agricultura E Agricultores No Perímetro Irrigado De Chókwè/Moçambique (Vol. 49). Universidade Federal Do Rio Grande Do Sul.2008.

CATSOSSA, L. A. O campo moçambicano no século XXI: dilemas e perspectivas do campesinato frente às grandes corporações do agronegócio. Revista Nera - Ano 20, Nº 38 - Dossiê - ISSN: 1806-6755, 2017.

CEMO. O impacto da política agrária em moçambique. Maputo. 2010.

\footnotetext{
${ }^{2}$ Disponivel em: https://www.youtube.com/watch?v=tEVra_aEWI
} 
Jalane, O. I.; Silva, E. V.; Sopchaki, C. H., Rev. Geociênc. Nordeste, Caicó, v.7, n.2, (Jul-Dez) p.123-130, 2021 130

COELHO, J. P. B. Estado, Comunidades e Calamidades Naturais no Moçambique Rural. In: Boaventura. S. (org.). Os caminhos da biodiversidade e dos conhecimentos rivais. Porto. Afrontamento, 2004. p. 217 -251.

CORREIA, A. M. A Agricultura Familiar versus A Agricultura De Subsistência no âmbito da Segurança Alimentar no Espaço dos países da CPLP. In: LIMA, S.C.; MAGALHÃES, R.; FONSECA, L.E.; CARVALHO, A.; (Org.). Segurança alimentar e nutricional na Comunidade Dos Países De Língua Portuguesa: Desafios e Perspectivas. Fiocruz. Rio de Janeiro. 2012.

Jornal da Noite. Maputo: STV, 02 de março 2019. Noticias.

Langa, D. A tempestade não passou em Magude. Jornal o País, Maputo, 18 jun. 2017. Disponível em: https://opais.co.mz/api/a-tempestade-naopassou-em-magude. Acessodo em 12. Fev.2020.

EMBRAPA - Monitoramento por Satélite. WebGIS Moçambique. Disponível em: < http://mapas.cnpm.embrapa.br/mocambique/mapa.html>. Acesso em: 20.fev.2020.

INE - INSTITUTO NACIONAL DE ESTATÍSTICA; Censo Agro -Pecuário 2009 -2010: Resultados Definitivos Moçambique. Maputo. 2011.

IPCC 2007 Climate Change 2007: IPCC Fourth Assessment Report, Climate Change 2007: Synthesis ReportSummary for Policymakers, Contribution of Working Groups I-III to the Fourth Assessment Report of the Intergovernmental Panel on Climate Change, eds. L. Bernstein et al. Cambridge, UK: Cambridge University Press, 2007.

LEWIS, P.; MONEM, M. A; IMPIGLIA, A. Impacts of climate change on farming systems and livelihoods in the near east and north africa - With a special focus on small-scale family Farming. Cairo, FAO.92 pp. Licence: CC BY-NYC-AS 3.0 IGO.2018.

MACAUHUB. Falta de água reduz a metade produção da empresa Bananalândia de Moçambique. 2018. Disponível em: https://macauhub.com.mo/pt/2018/01/12/pt-falta-deagua-reduz-a-metade-producao-da-empresa-bananalandiade-mocambique/. Acessado em: 18/04/2018.

MINISTÉRIO DA ADMINISTRAÇÃO ESTATAL (MAE). Perfil do distrito de Magude província de Maputo. Maputo Moçambique. 2014. Disponível em http://www.portaldogoverno.gov.mz. Acessado em: 23/12/2019.

MINISTÉRIO DA ADMINISTRAÇÃO ESTATAL (MAE). Perfil do distrito de Moamba província de Maputo. Maputo - Moçambique. 2005. Disponível em http://www.portaldogoverno.gov.mz. Acessado em: 23/12/2019.
MINISTÉRIO DA ADMINISTRAÇÃO ESTATAL (MAE) Perfil do distrito de Moamba província de Maputo. Maputo - Moçambique. 2014. Disponível em http://www.portaldogoverno.gov.mz. Acessado em: 23/12/2019.

MORTON, J. F. The impact of climate change on smallholder and subsistence agriculture.2007.

MOSCA, J. A agricultura familiar em Moçambique: Ideologias e Políticas. 2014. Revista Nera - Ano 20, No. 38 - Dossiê ISSN: 1806-6755, 2017.

SITOE, T. A evolução dos sistemas agrários no vale do Infulene, cidade da Matola -província de Maputo: Uma Abordagem Sistêmica. Anais do $4^{\circ}$ Congresso Brasileiro de Sistemas Centro Universitário de Franca Uni-FACEF. ISBN: 978-8587406-40-8, 2008. Disponível em http://legacy.unifacef.com.br/quartocbs/trabalhos_aprovado s.asp. Acessado em: 05/03/2020

SITOE, T. Agricultura familiar em moçambique estratégias de desenvolvimento sustentável. Maputo. 2005.

SMIT, B.; SKINNER, M.W. Adaptation options in agriculture to climate change: a typology. Mitigation and Adaptation Strategies for Global Change 7. (2002). p. 85-114. https://doi.org/10.1023/A:1015862228270.

UELE, D. I.; LYRA, G. B.; DE OLIVEIRA JÚNIOR, J. F. Variabilidade espacial e intranual das chuvas na região sul de Moçambique, África Austral. Revista Brasileira de Meteorologia,32(3). https://doi.org/10.1590/0102-77863230013.2017.

UNAC \& GRAIN. Os usurpadores de terras do Corredor de Nacala-Uma nova era de luta contra plantações coloniais no Norte de Moçambique. Maputo. 2015.

REASON, C.J.C. Tropical cyclone Dera, the unusual 2000/01tropical cyclone season in the southwest Indian Ocean and associated rainfall anomalies over Southern Africa. Meteorol Atmos Phys, v. 97, p. 181-188. 2007.

\section{AGRADECIMENTOS}

Os autores agradecem ao financiamentos dos projetos CAPES PGPSE Proc. 88887.123947/2016-00: Sistemas Ambientais costeiros e ocupação econômica do Nordeste; CAPES PRINT Proc. 88887.312019/2018-00: Integrated socio-environmental technologies and methods for territorial sustainability: alternatives for local communities in the context of climate change; e Programa CAPES/FUNCAP Proc. 88887.165948/2018-00: Apoio às Estratégias de Cooperação Científica do Programa de Pós-Graduação em Geografia - UFC.

Recebido em: 04/06/2020

Aceito para publicação em: 23/07/2021 